\title{
Pre-Erythrocytic Vaccines against Malaria
}

\author{
Camila Marques-da-Silva ${ }^{1,2}$, Kristen Peissig ${ }^{1,2}$ and Samarchith P. Kurup ${ }^{1,2, *(D)}$ \\ 1 Center for Tropical and Emerging Global Diseases, The University of Georgia, Athens, GA 30602, USA; \\ camilasilva@uga.edu (C.M.-d.-S.); kpeissig@uga.edu (K.P.) \\ 2 Department of Cellular Biology, The University of Georgia, Athens, GA 30602, USA \\ * Correspondence: samar@uga.edu
}

Received: 27 May 2020; Accepted: 20 July 2020; Published: 21 July 2020

\begin{abstract}
Malaria, caused by the protozoan Plasmodium, is a devastating disease with over 200 million new cases reported globally every year. Although immunization is arguably the best strategy to eliminate malaria, despite decades of research in this area we do not have an effective, clinically approved antimalarial vaccine. The current impetus in the field is to develop vaccines directed at the pre-erythrocytic developmental stages of Plasmodium, utilizing novel vaccination platforms. We here review the most promising pre-erythrocytic stage antimalarial vaccine candidates.
\end{abstract}

Keywords: malaria; pre-erythrocytic; vaccines; immunization; radiation attenuated; Sporozoites; GAPs; RAS

\section{Introduction}

Malaria is a mosquito-borne infectious disease caused by the eukaryotic pathogen, Plasmodium. Plasmodium has a complex life cycle, with distinct, antigenically discrete developmental stages in both vertebrate and invertebrate hosts. According to the World Health Organization (WHO), in 2018 an estimated 228 million new cases of malaria were reported globally, most of which were distributed among just nineteen countries in sub-Saharan Africa and the Indian subcontinent [1]. Exposure to malaria infections in pregnant women led to the delivery of about 872,000 children with low birthweight, indicating that malaria has broad economic and social impacts well beyond the clinical disease itself. Adult residents in malaria-endemic areas get repeatedly infected by Plasmodium and are known to develop naturally acquired immunity with age that prevent them from being clinically symptomatic [2]. Since these individuals do not typically receive antimalarial therapy nor develop sterilizing immunity from repeated infection [3], they are effective reservoirs of the Plasmodium parasites in the blood facilitating further transmission of the disease [4-6]. Hence, it is widely believed that elimination of malaria will not be achieved without safe, effective and affordable vaccines that offer protection from the different Plasmodium species causing malaria in humans.

In humans, Plasmodium sporozoites are delivered into the skin by the female Anopheles mosquitos during a blood meal. Subsequently, some of the motile sporozoites leave the bite site and travel through the blood-stream to find, invade and undergo development in the hepatocytes. The developmental progression of the Plasmodium parasites from the sporozoite stage inoculated in the skin to the completion of its development in the hepatocytes constitutes the asymptomatic, 'pre-erythrocytic stage' of malaria in its vertebrate host (Figure 1). Plasmodium development in the hepatocytes (liver-stage) is associated with significant changes in its gene expression and morphology. This process generates tens of thousands of merozoites that are released into the blood from the infected hepatocytes (in vesicles called merosomes), which infect red blood cells and start the symptomatic and highly pathogenic blood-stage of malaria. Preventing the progression of the malaria parasites from the liver-stage to its blood-stage not only prevents the onset of clinical disease and morbidity but also stems transmission. 
Hence, the development of vaccines targeting the pre-erythrocytic stages of malaria has been a priority in the field for the past few decades.

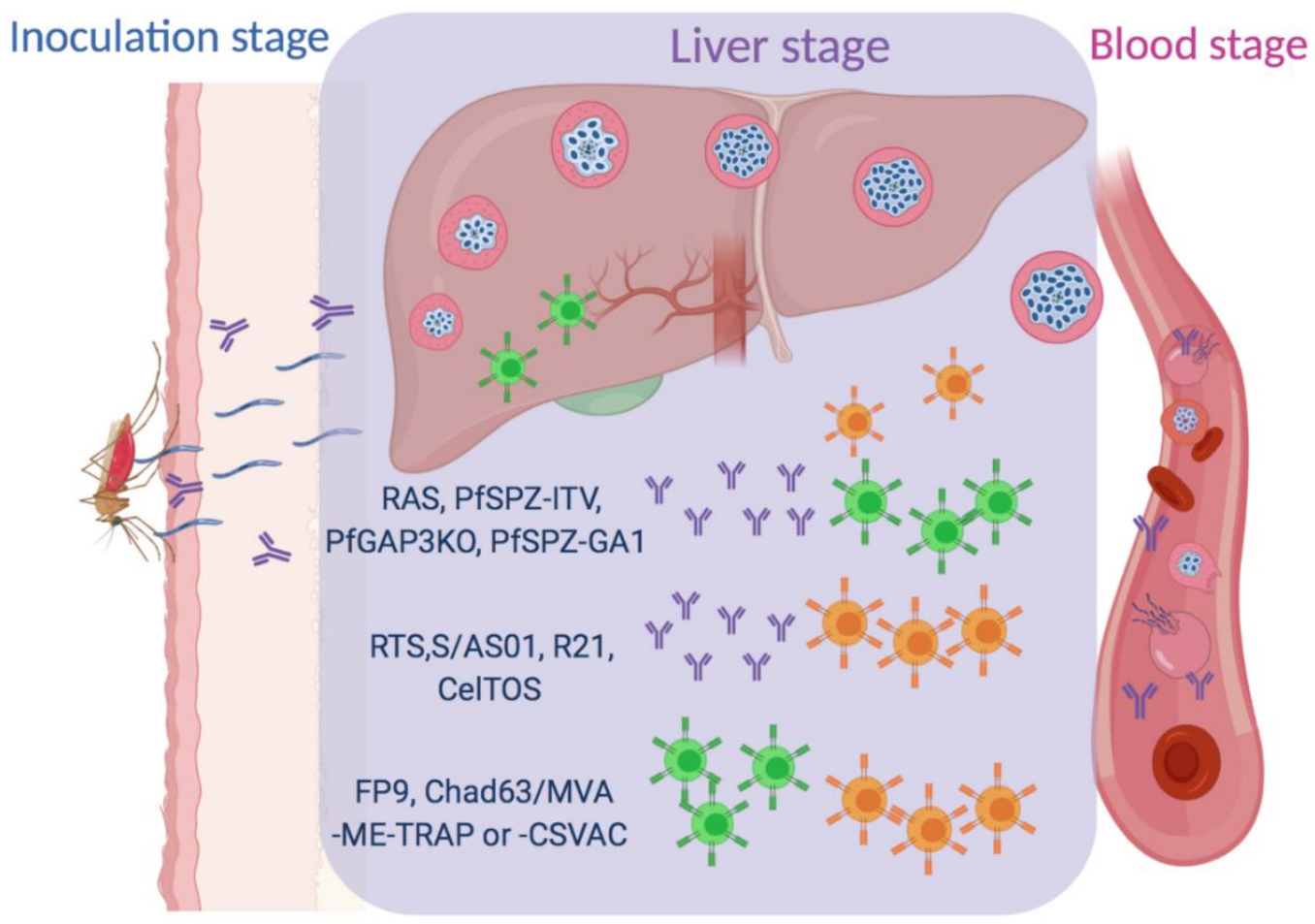

Figure 1. Plasmodium parasites are transmitted by infected Anopheles mosquitos when they draw a blood-meal from the vertebrate host, and concurrently inoculate the sporozoite stage of the parasite into the skin (inoculation stage). The motile sporozoites exit the dermis and enter the blood stream, travel to the liver and establish an infection in the hepatocytes (liver-stage). The sporozoites undergo asexual replication in the hepatocytes before budding off as hepatocyte plasma membrane-bound merosomes containing infective merozoites into the bloodstream, concluding the pre-erythocytic stage of malaria in the vertebrate hosts. Merosome rupture in the blood vessels to release the merozoites that invade red blood cells, to initiate the blood stage of malaria. Effective pre-erythrocytic-stage vaccines against malaria prevent the invasion and development of Plasmodium in the liver. While the RTS, S/AS01, $\mathrm{R} 21$ and CelTOS vaccines rely on the antibody and CD4 (orange) $\mathrm{T}$ cell responses generated against the constituent Plasmodium subunit antigens, the radiation-attenuated sporozoites (RAS), PfSPZ-ITV, PfGAP3KO and the PfSPZ-GA1 vaccines generate protective antibody, CD4 and CD8 (green) T cell responses against multiple Plasmodium antigens. The FP9, ChAd63/MVA-ME-TRAP or -CSVAC vaccines rely on the activation of both CD8 and CD4 T cell responses.

It is known that the replication of Plasmodium parasites in the liver is limited through the coordination of innate and adaptive immune responses [7,8]. Antimalarial vaccines can be broadly classified into three groups-pre-erythrocytic stage vaccines (PEVs), blood-stage vaccines (BSVs) and transmission-blocking vaccines (TBVs). In the PEVs and the BSVs, the hosts are protected by the Plasmodium-specific adaptive immune responses that prevent the progression of the infection. The TBVs, however, preclude transmission of malaria by generating neutralizing antibodies against the ookinete antigens in the hosts, which get taken up by the mosquitos along with the blood-meal [9]. PEVs have been a promising immunization strategy against malaria in human trials [10]. These vaccines prevent the onset of clinical disease by blocking the progression of Plasmodium to the blood-stage by priming protective adaptive immune responses against the Plasmodium sporozoite- or merozoite-stage antigens $[7,11]$. 
Malaria, like other eukaryotic pathogen infections, presents major challenges when it comes to vaccinations. Our incomplete understanding of the basic immunology of malaria, a relative lack of knowledge of the genetic variability of Plasmodium or the intricacies of its infection biology have all been major hurdles to our progress towards an effective vaccine against malaria. An ideal antimalarial vaccine would be safe and offer long-lasting Plasmodium-specific adaptive immune responses that are protective against the different Plasmodium species in humans. Other practical considerations like the potential for mass production, suitability of the administration route, vaccination schedule, dosage requirements, stability, shelf-life, cost-efficiency etc., are also important, given the target population for antimalarial vaccines live in the poorest parts of the world. Even though research over the years has made significant advances in the area of human malaria vaccines, we are yet to develop an antimalarial vaccine that is broadly protective and practical. We here review the most promising vaccination approaches targeting the pre-erythrocytic stage of malaria currently available or under development, along with the key studies that support them.

\section{Subunit Vaccines}

Antigen subunit vaccines are designed to prime protective immune responses against a limited number of immunodominant epitopes in a pathogen. The following are the key subunit vaccination approaches pertinent to human malaria infection.

\subsection{RTS, S/AS01 Vaccine}

Although the underlying mechanisms behind eliciting immune responses to the pre-erythrocytic stages of malaria are not fully understood, it is known that protection from new infections can be induced by vaccines that generate strong humoral and cellular immune responses against the sporozoite stage of Plasmodium in the mammalian host. While the sporozoite-specific antibodies generated in the immunized host preclude sporozoite invasion of the hepatocytes [12], sufficient numbers of sporozoite antigen-specific T cells help eliminate the Plasmodium-infected hepatocytes that present these epitopes [7]. The Circumsporozoite Protein (CSP), that forms an integral part of the surface-coat of the sporozoites, is vital in the interactions between the sporozoite and the host hepatocytes [13-15]. This has made the CSP a potential target antigen in pre-erythrocytic-stage antimalarial vaccines.

Thus, it is not surprising that one of the most prominent antimalarial subunit vaccines is the CSP-based RTS, S/AS01 recombinant vaccine (Mosquirix). The $58 \mathrm{kDa}$ CSP protein contains $37-49$ repeats of the NANP (N, asparagine; A, alanine; P, proline) amino acids and a smaller number of valine and aspartic acid residues [16]. The CSP C-terminal region contains T cell epitopes recognized by multiple Human Leukocyte Antigens DR isotype (HLA-DR) molecules [17,18]. The RTS, S/AS01 vaccine is composed of the P. falciparum (NF54 strain) CSP central repeat region with the NANP amino acid repeat sequence $(\mathrm{R})$ with a B-cell receptor epitope and immunodominant CD4 and CD8 T cell epitopes (T) fused to hepatitis B surface antigens (HBsAg, the $S$ antigen). In addition to this, three times more 'free' HBsAg antigen (S) is made available in the vaccine formulation to facilitate the self-assembly of the immunogen into virus-like particles [19]. Protection against malaria through RTS, S/AS01 vaccines is through the induction of high levels of both anti-CSP antibodies and CD4 T cells expressing IL-2, TNF, IFN- and the co-stimulatory marker CD40L [20,21]. The humoral and cellular immune responses generated by the RTS, S/AS01 vaccine were shown to offer immunity to mosquito bite challenge infections in human trials [22,23]. The RTS, S/AS01 vaccination also generated protective immune responses against Hepatitis $B$, in addition to against malaria [24].

Early formulations of the RTS, S moiety using alum or MPL (3-O-desacyl-4'-monophosphoryl lipid A) as an adjuvant did not induce a robust immune response. None of the six volunteers developed protective immunity with alum alone while two out of eight volunteers were protected with alum-MPL [20,25]. Subsequently, two similar adjuvant formulations made up of MPL and saponin (QS21) were developed for the RTS, S vaccine-AS01, a liposome formulation, and AS02, a squalene-based emulsion formulation. These liposomal adjuvants were efficient at generating 
a TLR4-mediated cytokine response as well as in inducing costimulatory molecules in the antigen-presenting cells [26,27]. RTS, S in combination with AS01 (RTS, S/AS01) generated stronger CSP-specific humoral and cellular immune responses [28,29], offered protection from experimental Plasmodium sporozoite challenges and was the first malaria vaccine to enter Phase III clinical trials [30]. It was shown that 18 months after the third booster dose, RTS, S/AS01 prevented 829 cases of clinical malaria episodes per 1000 children [31]. However, RTS, S/AS01 vaccination did not offer tangible immunity in the infants [31]. In phase III clinical trials in infants and children (ages 1-4), RTS, S/AS01 vaccination offered only $65 \%$ or $56 \%$ reduction (respectively) in severe malaria [32]. Nevertheless, the RTS, S/AS01 vaccine was approved for clinical use by the European regulatory bodies. In the 'Expanded Program of Immunization' in Africa, 8-12 week old children were offered RTS, S/AS01 along with the various childhood vaccines, with the RTS, S/AS01 booster dose delivered at forty-eight months post primary vaccination [33,34]. The co-administration of RTS, S/AS01 with the yellow fever and measles-rubella vaccines and vitamin A supplementation in children helped the program offer it without increasing the number of immunization-clinic visits required [33].

The RTS, S/AS01 vaccine, despite its clinical use, is far from being the ideal malaria vaccine. The protection offered is inadequate and wanes over time [31]. The CSP antigen, which the RTS, $S$ vaccine primarily targets, is expressed in the sporozoite stage of Plasmodium, which typically invades the liver cells in under half an hour of being inoculated into humans $[35,36]$. The merozoite stage of the parasite that the sporozoite transforms itself into, and emerges from the hepatocytes 7-10 days later causing clinical malaria, is unrecognized by the RTS, S-induced antibodies or T cell responses. Preventing any sporozoites from reaching the liver in the short window of opportunity available appears a practically difficult task even with strong circulating antibody responses [30]. In addition, waning CSP-specific immune responses from RTS, S/AS01 vaccination is a significant shortcoming. In RTS, S/AS01 infant vaccination programs, worn-off immunity has resulted in rebound or age-shift of infections [37]. Besides that, the RTS, S vaccine has also raised some safety concerns in children [37,38]. The RTS, S vaccine does not possess the CSP N-terminal region in its formulation, although the naturally acquired antibodies to the CSP N-terminal are associated with protection from malaria [39,40]. When longer synthetic peptides containing the entire $\mathrm{N}$ - or C-termini of CSP were prepared with suitable adjuvants, stronger, more effective $\mathrm{T}$ cell and antibody responses were generated [41,42]. The development of better, more potent adjuvants may also help offer stronger immune responses that are sustained longer. The structural data emerging from CSP-specific antibodies could also provide key insights into improving the CSP-based vaccines [43]. The advent of novel vaccination approaches and platforms may help develop better CSP-based antimalarial vaccines in the future $[44,45]$.

\section{2. $R 21$}

$\mathrm{R} 21$ is considered the next generation antimalarial subunit vaccine, and is an improved version of the RTS, S/AS01 vaccine. The R21 design incorporates a higher proportion of PfCSP C-terminus bound to HBsAg N-terminus without the three-fold molar excess of HBsAg found in RTS, S/AS01 [20,46]. In this way, more CSP antigen is displayed on the vaccine particle surface, mimicking the higher CSP epitope concentration on the Plasmodium sporozoite surface [43]. This enhanced B cell activation led to stronger anti-CSP humoral immune responses [47]. In BALB/c mice, R21 was immunogenic even at very low doses. When administered with the adjuvants Abisco-100 and Matrix-M, R21 elicited protection against the PfCSP-transgenic P. berghei sporozoite challenge [48]. A clinical trial using R21 with the AS01 adjuvant was well-tolerated and induced a strong anti-CSP antibody response [30]. R21 is now under evaluation in Phase 1/2a clinical trials [49].

\subsection{Viral-Vectored Vaccines}

Another strategy used to formulate an antigen-subunit vaccine for malaria is to utilize viral vectors to deliver the antigens. Homologous or heterologous prime-boost vaccinations using viruses encoding the Plasmodium pre-erythrocytic antigens would induce cell-mediated immune responses [48]. One of 
the earliest attempts at using this approach employed the use of the Fowlpox Virus 9 (FP9) or the attenuated vaccinia virus (Ankara, MVA) as vectors, either independently or in combination [50-52] and expressing the insert ME-TRAP. ME is a string of 20 epitopes from the P. falciparum pre-erythrocytic stage that are predominantly targeted by the CD8 T cells [53]. ME is fused to the P. falciparum (T9/96 strain) pre-erythrocytic-stage protein, thrombospondin-related adhesion protein (TRAP) to make ME-TRAP [37] that targets multiple developmental stages of the Plasmodium parasite in the mammalian host [38].

Although priming with FP9-ME-TRAP followed by MVA-ME-TRAP booster induced antigen-specific CD4 and CD8 $\mathrm{T}$ cell responses, only two out of the five vaccinated subjects were protected [51]. This resulted in the transition to the ChAd63/MVA ME-TRAP vaccine [54,55]. The ChAd63/MVA ME-TRAP vaccine uses the chimpanzee adenovirus 63 (ChAd63) in addition to the MVA and the ME-TRAP antigen. Prime-boost immunization with ChAd63/MVA ME-TRAP generated high levels of effector CD4 and CD8 T cell responses [55] and in phase 1/2a clinical trials elicited immune protection from heterologous sporozoite challenge in $21 \%$ and delayed time to blood stage parasitemia in $36 \%$ of the immunized volunteers [54]. In phase $2 \mathrm{~b}$ clinical trials with this vaccination approach, while Kenyan men showed a $67 \%$ reduction in risk of malaria infection, no such benefit was observed in Senegalese men [56,57]. This suggested that the ChAd63/MVA ME-TRAP vaccine may not have a reliable, consistent efficacy in the genetically heterogenous malaria-endemic regions.

Other alternatives to the ME-TRAP antigen have been explored for antimalarial viral-vector vaccines. One of these is CSVAC, which encodes PfCSP with a truncated C-terminal lacking the 14 amino acids corresponding to the CSP GPI anchor moiety [58]. ChAd63/MVA-CSVAC presented good safety profiles but had no significant improvement in immunogenicity. It is, however, not surprising that ME-TRAP is a better antigenic insert for viral-vectored malaria vaccines [56,58] since cell-mediated immunity is the primary protective tool in viral-vectored vaccines. More recently, a viral-vectored malaria vaccine that combined PfTRAP with the highly conserved merozoite proteins, liver-stage antigen 1 (LSA1) and the liver-stage-associated protein 2 (LSAP2), was developed. Nevertheless, neither its immunogenicity nor protective efficacy were significantly impacted with the inclusion of these two proteins [59-61].

The relative success of the viral-vectored malaria vaccines is promising due to their ability to induce high levels of $\mathrm{T}$ cell responses. Yet, their efficacy in the malaria-endemic regions have been less than ideal. It is possible that inserting more immunogenic Plasmodium antigens, as they are identified, into the viral vectors may change this. Additionally, a combination of viral-vectored malaria vaccines with RTS, S/AS01 may also improve the overall vaccine efficacy by the generation of protective CD8 and CD4 $\mathrm{T}$ cell responses along with the strong anti-CSP antibodies.

\subsection{CelTOS}

Besides the CSP and TRAP proteins, the cell-traversal protein for ookinetes and sporozoites (CelTOS) of Plasmodium has been considered an attractive target antigen for the development of pre-erythrocytic malaria vaccines. CelTOS is a $25-\mathrm{kDa}$ protein vital for the ookinete traversal in the mosquito midgut, as well as for the sporozoite infection of liver cells in the human host, which also primes a strong immune response [62]. Additionally, the CelTOS protein sequence is highly conserved among the various Plasmodium species $[63,64]$. In both inbred and outbred mice, immunization with recombinant $P f$ CelTOS adjuvanted with Montanide ISA 720 resulted in potent humoral and cellular immune responses that induced cross-reactive immunity against $P$. berghei sporozoite challenge [65]. More recently, it was shown that vaccination with recombinant $P f C e l T O S$ when formulated with suitable adjuvants would induce high-affinity antibodies that inhibit $P$. falciparum infection of Anopheles stephensi mosquitos [66], suggesting that $P f C e l T O S$ may be an effective vaccine to not only prevent clinical infection in the human host but also transmission of the infection to and from mosquitos. Despite the positive results, the CelTOS vaccine will require more refinement before being considered a potential malaria vaccine. 
A key deficiency of subunit vaccines is their inability to generate long-standing immunity. Novel adjuvants and vaccine delivery platforms may help induce long-lived plasma cells to help improve the longevity of subunit vaccine-induced memory responses. This was demonstrated by the partial success of the preclinical study combining the FP9 and the MVA viral vectors with a CSP-based Hepatitis B virus core particle [67]. Another major shortcoming of the subunit vaccines, particularly against complex eukaryotic pathogens with multiple life-cycle stages in a host, is that the immune responses generated against a single or a few epitopes are often not enough to offer effective immunity. Although using multivalent antigenic preparations might negate this shortcoming to some extent, the problem is exacerbated by the inherent genetic diversity of the Plasmodium parasites. For instance, the RTS, S/AS01 vaccine efficacy is noticeably lower when challenge infections do not match the 3D7 strain-derived CSP isotype. By combining multiple antigens from different stages of Plasmodium development in the mammalian host, targeting highly conserved Plasmodium antigens with fewer polymorphisms or using novel adjuvants that induce stronger innate and adaptive immune response, some of the deficiencies of subunit antimalarial vaccines may be overcome at least partially.

\section{Whole Sporozoite Vaccines}

It has been demonstrated that $P$. falciparum infection initiated by the sporozoites, when arrested in its liver stage of development, provide immunity from P. falciparum challenge in humans [68]. Plasmodium infection can be prevented from causing clinical malaria by using either chemoprophylactic antimalarial drugs that are specific to blood-stage malaria, or by using attenuated Plasmodium (by irradiation or targeted genetic alteration) parasites that prevent its progression beyond the liver. While the chemoprophylactic drugs prevent the progression of Plasmodium beyond the first round of blood-stage infection, the attenuated Plasmodium do not complete their liver-stage development and fail to enter the blood-stage altogether.

\subsection{PfSPZ with Chemoprophylaxis (PfSPZ ITV)}

The infection treatment vaccination (ITV) approach in malaria involves infection with wild-type sporozoites (SPZ) under the blood-stage-specific antimalarial drug coverage. Compared to the other whole-sporozoite vaccination approaches, the presence of an abortive blood-stage infection in ITV offers the added advantage of the generation of humoral immune responses against blood-stage malaria antigens. Rodent studies indicated that ITV with chloroquine (CQ) offered protection through the generation of IFN- ${ }^{+}$CD8 T cell responses [69] directed at the liver-stage of malaria [70].

The early human whole-sporozoite vaccination studies began with controlled human malaria infections (CHMI) in conjunction with CQ prophylaxis to prevent blood-stage malaria infection. This immunization method was shown to be protective against homologous strain challenges in $100 \%$ of the vaccinated volunteers [71], with some volunteers remaining immune even after 2 years [72]. Protection was shown to be mediated by memory T cells producing IFN- $\gamma$, TNF, and IL-2 [71]. However, limited protection was observed following challenge with a heterologous strain of $P$. falciparum, indicating the inadequacy of this approach to protect against the parasite's genetic diversity [73]. New pharmacological alternatives to chloroquine such as atovaquone/proguanil, azithromycin and pyrimethamine are being developed for CHMI, along with different regimens for immunization [74]. Nevertheless, the risk of not achieving complete parasitological cure with drug treatment, the emergence of drug-resistance [75] and the need for close monitoring of vaccinated subjects with rigorous follow-up, pose major technical and practical hinderances to using this approach as a strategy for mass immunization in endemic areas.

\subsection{Radiation Attenuated Sporozoites (RAS)}

Gamma irradiation of Plasmodium sporozoites induces DNA damage in the parasites, leading to the early arrest of its development in the liver. The RAS vaccine contains gamma-irradiated SPZ isolated from the salivary glands of infected mosquitos [76]. Inoculation of RAS leads to abortive 
infections in the liver that also help prime protective cell and humoral immune responses $[77,78]$. In the RAS vaccination, protection is mediated by both the humoral immune responses that inhibit the sporozoite motility and invasion of hepatocytes and the $\mathrm{T}$ cell-mediated cellular responses directed at the infected hepatocytes [79]. Notably, studies using the mouse model demonstrated that the route of inoculation was also critical in the ability of the RAS vaccines to impart protection. Subcutaneous or intradermal routes of inoculation required 7-10 times more $P$. yoelii RAS to confer protection, suggesting that the IV route of administration is the most efficient to generate $\mathrm{T}$ cell responses in animal models [78,80-82]. A subsequent study showed that intravenous delivery of $P$. falciparum RAS was crucial to induce high levels of circulating and liver-resident $P$. falciparum-specific CD8 T cells in macaques [83]. Mice immunized with $P$. berghei RAS were also protected from both homologous and heterologous (with P. vinckei) [84] species challenges.

The first clinical trials with P. falciparum RAS in humans relied on immunization via mosquito bites [74,85]. Although the subcutaneous and intradermal inoculation of the RAS vaccine would more practical, using these resulted in suboptimal immune responses and protection compared to the intravenous route [83]. Intravenous immunization with P. falciparum RAS showed that it reduced the risk of malaria infection in malaria-endemic regions, with the protective immunity being associated with robust P. falciparum specific CD8 T cell responses [86]. Although the RAS vaccine has been shown to be protective in controlled human trials, one main drawback of RAS is that the parasites are inconsistently, and in some instances incompletely attenuated, both of which can result in ineffective immunity or breakthrough malaria infections [87]. This has led to the push for genetically attenuated sporozoite vaccines where consistent attenuation of sporozoites could be achieved. In addition, utilizing RAS vaccination against malaria face many technical challenges regarding its delivery and administration. RAS vaccines, like other whole-sporozoite vaccines, require the maintenance of a cold-chain during its transport and storage to retain its stability and viability. These are significant challenges in the impoverished malaria-endemic regions.

\subsection{Genetically-Attenuated Parasites (GAPs)}

Considering the relative success of the whole-sporozoite based vaccines, novel advances in genetic manipulation were used to develop a targeted approach to attenuate Plasmodium parasites. By modifying or deleting key essential genes, Plasmodium parasites were generated that were incapable of transitioning from its liver-stage to the blood-stage of infection, thereby preventing the onset of clinical malaria. This approach to attenuate Plasmodium can be tailored to not affect the viability of Plasmodium in its blood-stage and the mosquito vector, infectivity in the mosquitoes, or the transition to the sporozoite stage, to together facilitate generating the transgenic parasites [88]. Targeted genetic alteration of Plasmodium also generates a homogenous population of attenuated parasites with a distinct genetic identity. The attenuated status of this unique clonal population also does not rely on external technical variables like the radiation dosage (in RAS) or host drug metabolism (in ITV) [89-91].

In order to identify the target genes, which when ablated would prevent the progression of the Plasmodium parasites beyond its liver stage, a differential gene expression study was performed [88,92] in the liver-stage of malaria [93]. The UIS3 and UIS4 genes, that encode proteins in the parasitophorous vacuole membrane (PVM) of Plasmodium liver-stage, were identified as possible targets for gene disruption based on this strategy. In mice, $P$. berghei $(\mathrm{Pb})$ liver-stage development was disrupted in both uis3 ( $\mathrm{Pb}$ uis3KO) [88] and uis4 ( $\mathrm{Pb}$ uis4KO) [94] single-knockout parasites and immune protection was conferred upon immunization with either of these parasites; this was dependent on the CD8 $\mathrm{T}$ cell responses generated [94]. Nevertheless, breakthrough blood-stage infection was occasionally seen using $\mathrm{Pb}$ uis $4 \mathrm{KO}$ and was thus not a viable vaccine candidate. Immunization of mice with double-knockout of uis3 and uis4 ( $\mathrm{Pb}$ uis3/uis4dKO) prevented any breakthrough parasitemia, while concurrently generating IFN- $\gamma$-producing effector and memory CD8 $\mathrm{T}$ cell responses that offered immune protection lasting up to 6 months [95]. 
P36, P36p (P52) and B9 were additional candidate genes identified as targets for genetic attenuation, due also to them being highly conserved among the different Plasmodium species [96]. All three proteins are members of the 6-Cys protein family and were shown to be essential for the liver-stage development of the Plasmodium parasite. In mice, although the $\mathrm{Pb} P 36 \mathrm{KO}$ infection induced protective immunity, breakthrough parasitemia was observed [97]. Similarly, vaccination with $\mathrm{Pb} B 9 \mathrm{KO}$ also led to breakthrough infections [98]. However, P. yoelii (Py) p52/p36dKO-vaccinated BALB/c mice exhibited no breakthrough parasitemia and achieved protective immunity from subsequent $P$. yoelii sporozoite challenge [99]. Breakthrough parasitemia was later observed in C57BL/6 mice infected with $\mathrm{Pb}$ p52/p36dKO parasites, suggesting incomplete attenuation of these GAPs [100]. Another gene, the sporozoite asparagine-rich protein 1 (SAP1), observed to be essential for the liver-stage development of $P$. yoelii, was ablated to generate $P y$ sap $1 \mathrm{KO}$. The $P y$ sap $1 \mathrm{KO}$ parasites exhibited arrest of development in the liver-stage with no breakthrough parasitemia, conferring long-lasting immune protection against wild-type sporozoite infection [101].

An ortholog of SAP1 called SLARP was also studied, and Pb slarpKO showed similar results to $P y$ sap1KO, arresting early in liver-stage development with no breakthrough parasitemia [101]. However, Py slarp1KO immunization did not confer long-lasting protective immunity [101]. The deletion of the $F a b B / F$ gene involved in fatty acid synthesis resulted in P. yoelii parasites that arrested late in the liver stage [89]. Immunization with $P y$ FabB/FKO elicited a high magnitude of CD8 T cell effector and memory response in both inbred and outbred mice [91]. When compared to the RAS that often arrested early in its liver-stage development, the GAPs that progressed into late-liver-stage engendered higher magnitudes of effector and memory CD8 T cell responses, possibly also directed at a more diverse set of antigens, resulting in better protection from secondary challenges [91]. This finding suggested that late-arresting GAPs may be more reliable as a vaccine candidate, compared to either the early-arresting GAPs or RAS vaccines for malaria. The rodent studies demonstrated that GAP vaccination is protective and mostly safe, pushing the field toward developing GAP vaccines for human malaria [91].

The first clinical trial using GAPs evaluated the safety and immunogenicity of $P$. falciparum lacking the two genes-p52 and p36. The Pf p52/p36dKO inoculation by mosquito bite was well-tolerated, but one out of the six volunteers develop breakthrough blood-stage malaria infection [102], similar to the observation made in the rodent studies with the $\mathrm{Pb} p 52 / p 36 \mathrm{dKO}$ parasites [100]. A triple-gene deletion GAP (PfGAP3KO) was subsequently created, deleting $p 52$, p36, and sap1 to further reduce the chances of breakthrough parasitemia. Administration of PfGAP3KO by mosquito bites in volunteers showed no breakthrough blood-stage P. falciparum infection. Considerable anti-CSP antibody titers were generated in all test subjects with significant IFN- $\gamma$, IL-2 and TNF cytokine levels detected in the serum [90]. Inspired by the positive results from PfGAP3KO, another GAP vaccine was developed, called the PfSPZ-GA1, lacking B9 and SLARP [98]. Although PfSPZ-GA1 offered acceptable safety profiles in Phase I/IIa clinical trials, only three out of the 25 vaccinated volunteers showed protective immunity to mosquito-bite challenge [103].

Given that GAP vaccines are, by design, precisely genetically engineered to prevent the progression of Plasmodium beyond its liver-stage of development, they are seen as better pre-erythrocytic malaria vaccines compared to irradiated sporozoites. GAP vaccines are also homogenously attenuated and more broadly immunogenic, making it the safer and better choice for field application [104]. By identifying additional target genes that can be knocked-out to generate GAPs, better vaccine candidates may be generated in the future. A novel approach to generating GAPs is the use of the CRISPR-Cas9 system to attenuate parasites [105-108]. Although the whole-sporozoite vaccination strategies described above generate protective immune responses, the requirement for intravenous needle delivery of the sporozoites to achieve this is practically challenging in malaria-endemic areas. This caveat also makes the whole-sporozoite vaccinations more difficult in infants and younger children, who constitute the key target age groups for a malaria vaccine [80]. Transgenically expressing strong pathogen-associated molecular patterns (PAMPs) in the GAPs may help enhance the immunogenicity of the RAS-based vaccines, making them more immunogenic and effective when delivered through intravenous or other 
parenteral routes [109]. The logistics of cryopreservation, maintenance of cold-chain and the need for adequately trained personnel for intravenous delivery of the vaccine are hindrances for the use of any live-attenuated sporozoite based vaccines in mass vaccination campaigns in malaria-endemic areas.

\section{Conclusions}

The field of malaria vaccine development has faced many challenges over the years. The genetic and biological complexities of the Plasmodium parasite, presence of multiple, antigenically distinct life cycle stages in the mammalian host, the involvement of mosquito vectors and the prevalence of malaria in the poorest, most populous parts of the world are just a few of these. These have also impeded our ability to understand malaria biology and effectively pursue vaccination strategies to combat this disease. Gaining a better mechanistic understanding of the immune responses mounted against Plasmodium infection might help us devise suitable vaccination approaches that effectively prevent the infection. A deeper understanding of Plasmodium development in its pre-erythrocytic stage may help unveil novel antigenic targets, amenable to improved vaccination approaches. Together, these can help develop new immunization strategies for the induction of a more effective and functional protective immunity to malaria. Despite the challenges, a great deal of progress has been made in the field of malaria vaccinology. We have made great strides in identifying and testing novel vaccine candidates and resolving the immunological metrics of protection in human and animal models [7,110]. Based on our current understanding of how immune responses help clear Plasmodium infection in the liver to prevent the onset of blood-stage malaria, the possibility of developing a clinically applicable, highly effective, conventional subunit vaccine against malaria appears less likely. Althoug live-attenuated vaccination approaches hold the most promise in terms of inducing protective immune responses at the moment, we have ways to go before these can be safely deployed in the field. We believe that future studies that systematically dissect the immunobiology of liver-stage malaria will help drive the design, development and optimization of effective immunization strategies that will one day help eradicate malaria.

Author Contributions: C.M.-d.-S., K.P. and S.P.K. drafted and edited the manuscript. All authors have read and agreed to the published version of the manuscript.

Funding: This research received no external funding.

Acknowledgments: We apologize to the countless researchers whose contributions to the field of malaria vaccines could not be included in this manuscript because of the space limitations. We thank Rahul Vijay (University of Iowa) for his suggestions and inputs in preparing this manuscript.

Conflicts of Interest: The authors declare no conflict of interests.

\section{References}

1. WHO. Malaria Eradication: Benefits, Future Scenarios \& Feasibility. In A Report of the Strategic Advisory Group on Malaria Eradication; WHO: Geneva, Switzerland, 2018.

2. Crompton, P.D.; Moebius, J.; Portugal, S.; Waisberg, M.; Hart, G.; Garver, L.S.; Miller, L.H.; Barillas-Mury, C.; Pierce, S.K. Malaria immunity in man and mosquito: Insights into unsolved mysteries of a deadly infectious disease. Annu. Rev. Immunol. 2014, 32, 157-187. [CrossRef] [PubMed]

3. Tran, T.M.; Li, S.; Doumbo, S.; Doumtabe, D.; Huang, C.Y.; Dia, S.; Bathily, A.; Sangala, J.; Kone, Y.; Traore, A.; et al. An intensive longitudinal cohort study of Malian children and adults reveals no evidence of acquired immunity to Plasmodium falciparum infection. Clin. Infect. Dis. 2013, 57, 40-47. [CrossRef] [PubMed]

4. Odongo-Aginya, E.; Ssegwanyi, G.; Kategere, P.; Vuzi, P.C. Relationship between malaria infection intensity and rainfall pattern in Entebbe peninsula, Uganda. Afr. Health Sci. 2005, 5, 238-245. [CrossRef] [PubMed]

5. Midekisa, A.; Beyene, B.; Mihretie, A.; Bayabil, E.; Wimberly, M.C. Seasonal associations of climatic drivers and malaria in the highlands of Ethiopia. Parasites Vectors 2015, 8, 339. [CrossRef] [PubMed]

6. Saute, F.; Aponte, J.; Almeda, J.; Ascaso, C.; Vaz, N.; Dgedge, M.; Alonso, P. Malaria in southern Mozambique: Incidence of clinical malaria in children living in a rural community in Manhica district. Trans. R. Soc. Trop. Med. Hyg. 2003, 97, 655-660. [CrossRef] 
7. Kurup, S.P.; Butler, N.S.; Harty, J.T. T cell-mediated immunity to malaria. Nat. Rev. Immunol. 2019, 19, 457-471. [CrossRef]

8. Liehl, P.; Zuzarte-Luis, V.; Chan, J.; Zillinger, T.; Baptista, F.; Carapau, D.; Konert, M.; Hanson, K.K.; Carret, C.; Lassnig, C.; et al. Host-cell sensors for Plasmodium activate innate immunity against liver-stage infection. Nat. Med. 2014, 20, 47-53. [CrossRef]

9. Palatnik-de-Sousa, C.B.; Nico, D. The Delay in the Licensing of Protozoal Vaccines: A Comparative History. Front. Immunol. 2020, 11, 204. [CrossRef]

10. Aide, P.; Bassat, Q.; Alonso, P.L. Towards an effective malaria vaccine. Arch. Dis. Child. 2007, 92, 476-479. [CrossRef]

11. Holz, L.E.; Fernandez-Ruiz, D.; Heath, W.R. Protective immunity to liver-stage malaria. Clin. Transl. Immunol. 2016, 5, e105. [CrossRef]

12. Garcia, J.E.; Puentes, A.; Patarroyo, M.E. Developmental biology of sporozoite-host interactions in Plasmodium falciparum malaria: Implications for vaccine design. Clin. Microbiol. Rev. 2006, 19, 686-707. [CrossRef] [PubMed]

13. Menard, R. The journey of the malaria sporozoite through its hosts: Two parasite proteins lead the way. Microbes Infect. 2000, 2, 633-642. [CrossRef]

14. Pradel, G.; Garapaty, S.; Frevert, U. Proteoglycans mediate malaria sporozoite targeting to the liver. Mol. Microbiol. 2002, 45, 637-651. [CrossRef] [PubMed]

15. Rathore, D.; McCutchan, T.F.; Garboczi, D.N.; Toida, T.; Hernaiz, M.J.; LeBrun, L.A.; Lang, S.C.; Linhardt, R.J. Direct measurement of the interactions of glycosaminoglycans and a heparin decasaccharide with the malaria circumsporozoite protein. Biochemistry 2001, 40, 11518-11524. [CrossRef] [PubMed]

16. McCutchan, T.F.; Kissinger, J.C.; Touray, M.G.; Rogers, M.J.; Li, J.; Sullivan, M.; Braga, E.M.; Krettli, A.U.; Miller, L.H. Comparison of circumsporozoite proteins from avian and mammalian malarias: Biological and phylogenetic implications. Proc. Natl. Acad. Sci. USA 1996, 93, 11889-11894. [CrossRef]

17. Good, M.F.; Pombo, D.; Quakyi, I.A.; Riley, E.M.; Houghten, R.A.; Menon, A.; Alling, D.W.; Berzofsky, J.A.; Miller, L.H. Human T-cell recognition of the circumsporozoite protein of Plasmodium falciparum: Immunodominant T-cell domains map to the polymorphic regions of the molecule. Proc. Natl. Acad. Sci. USA 1988, 85, 1199-1203. [CrossRef]

18. Bermudez, A.; Cifuentes, G.; Guzman, F.; Salazar, L.M.; Patarroyo, M.E. Immunogenicity and protectivity of Plasmodium falciparum EBA-175 peptide and its analog is associated with alpha-helical region shortening and displacement. Biol. Chem. 2003, 384, 1443-1450. [CrossRef]

19. Cohen, J.; Nussenzweig, V.; Nussenzweig, R.; Vekemans, J.; Leach, A. From the circumsporozoite protein to the RTS, S/AS candidate vaccine. Hum. Vaccines 2010, 6, 90-96. [CrossRef]

20. Gordon, D.M.; McGovern, T.W.; Krzych, U.; Cohen, J.C.; Schneider, I.; LaChance, R.; Heppner, D.G.; Yuan, G.; Hollingdale, M.; Slaoui, M.; et al. Safety, immunogenicity, and efficacy of a recombinantly produced Plasmodium falciparum circumsporozoite protein-hepatitis B surface antigen subunit vaccine. J. Infect. Dis. 1995, 171, 1576-1585. [CrossRef]

21. White, M.T.; Bejon, P.; Olotu, A.; Griffin, J.T.; Riley, E.M.; Kester, K.E.; Ockenhouse, C.F.; Ghani, A.C. The relationship between RTS, S vaccine-induced antibodies, CD4(+) T cell responses and protection against Plasmodium falciparum infection. PLoS ONE 2013, 8, e61395. [CrossRef]

22. Casares, S.; Brumeanu, T.D.; Richie, T.L. The RTS, S malaria vaccine. Vaccine 2010, 28, 4880-4894. [CrossRef] [PubMed]

23. Sun, P.; Schwenk, R.; White, K.; Stoute, J.A.; Cohen, J.; Ballou, W.R.; Voss, G.; Kester, K.E.; Heppner, D.G.; Krzych, U. Protective immunity induced with malaria vaccine, RTS, S, is linked to Plasmodium falciparum circumsporozoite protein-specific CD4+ and CD8+ T cells producing IFN-gamma. J. Immunol. 2003, 171, 6961-6967. [CrossRef] [PubMed]

24. Valea, I.; Adjei, S.; Usuf, E.; Traore, O.; Ansong, D.; Tinto, H.; Owusu Boateng, H.; Some, A.M.; Buabeng, P.; Vekemans, J.; et al. Long-term immunogenicity and immune memory response to the hepatitis B antigen in the RTS, S/AS01E malaria vaccine in African children: A randomized trial. Hum. Vaccines Immunother. 2020, 16, 1-7. [CrossRef] [PubMed]

25. Stassijns, J.; Bollaerts, K.; Baay, M.; Verstraeten, T. A systematic review and meta-analysis on the safety of newly adjuvanted vaccines among children. Vaccine 2016, 34, 714-722. [CrossRef] [PubMed] 
26. Fernandez-Tejada, A.; Chea, E.K.; George, C.; Gardner, J.R.; Livingston, P.O.; Ragupathi, G.; Tan, D.S.; Gin, D.Y. Design, synthesis, and immunologic evaluation of vaccine adjuvant conjugates based on QS-21 and tucaresol. Bioorganic Med. Chem. 2014, 22, 5917-5923. [CrossRef]

27. Marty-Roix, R.; Vladimer, G.I.; Pouliot, K.; Weng, D.; Buglione-Corbett, R.; West, K.; MacMicking, J.D.; Chee, J.D.; Wang, S.; Lu, S.; et al. Identification of QS-21 as an Inflammasome-activating Molecular Component of Saponin Adjuvants. J. Biol. Chem. 2016, 291, 1123-1136. [CrossRef] [PubMed]

28. Leroux-Roels, G.; Leroux-Roels, I.; Clement, F.; Ofori-Anyinam, O.; Lievens, M.; Jongert, E.; Moris, P.; Ballou, W.R.; Cohen, J. Evaluation of the immune response to RTS, S/AS01 and RTS, S/AS02 adjuvanted vaccines: Randomized, double-blind study in malaria-naive adults. Hum. Vaccines Immunother. 2014, 10, 2211-2219. [CrossRef] [PubMed]

29. Asante, K.P.; Abdulla, S.; Agnandji, S.; Lyimo, J.; Vekemans, J.; Soulanoudjingar, S.; Owusu, R.; Shomari, M.; Leach, A.; Jongert, E.; et al. Safety and efficacy of the RTS, S/AS01E candidate malaria vaccine given with expanded-programme-on-immunisation vaccines: 19 month follow-up of a randomised, open-label, phase 2 trial. Lancet Infect. Dis. 2011, 11, 741-749. [CrossRef]

30. Molina-Franky, J.; Cuy-Chaparro, L.; Camargo, A.; Reyes, C.; Gomez, M.; Salamanca, D.R.; Patarroyo, M.A.; Patarroyo, M.E. Plasmodium falciparum pre-erythrocytic stage vaccine development. Malar. J. 2020, 19, 56. [CrossRef]

31. The RTS, S Clinical Trials Partnership. Efficacy and Safety of the RTS, S/AS01 Malaria Vaccine during 18 Months after Vaccination: A Phase 3 Randomized, Controlled Trial in Children and Young Infants at 11 African Sites. PLoS Med. 2014, 11. [CrossRef]

32. Bejon, P.; Lusingu, J.; Olotu, A.; Leach, A.; Lievens, M.; Vekemans, J.; Mshamu, S.; Lang, T.; Gould, J.; Dubois, M.C.; et al. Efficacy of RTS, S/AS01E vaccine against malaria in children 5 to 17 months of age. N. Engl. J. Med. 2008, 359, 2521-2532. [CrossRef]

33. Otieno, L.; Guerra Mendoza, Y.; Adjei, S.; Agbenyega, T.; Agnandji, S.T.; Aide, P.; Akoo, P.; Ansong, D.; Asante, K.P.; Berkley, J.A.; et al. Safety and immunogenicity of the RTS, S/AS01 malaria vaccine in infants and children identified as HIV-infected during a randomized trial in sub-Saharan Africa. Vaccine 2020, 38, 897-906. [CrossRef] [PubMed]

34. Agnandji, S.T.; Asante, K.P.; Lyimo, J.; Vekemans, J.; Soulanoudjingar, S.S.; Owusu, R.; Shomari, M.; Leach, A.; Fernandes, J.; Dosoo, D.; et al. Evaluation of the safety and immunogenicity of the RTS, S/AS01E malaria candidate vaccine when integrated in the expanded program of immunization. J. Infect. Dis. 2010, 202, 1076-1087. [CrossRef]

35. Mota, M.M.; Pradel, G.; Vanderberg, J.P.; Hafalla, J.C.; Frevert, U.; Nussenzweig, R.S.; Nussenzweig, V.; Rodriguez, A. Migration of Plasmodium sporozoites through cells before infection. Science 2001, 291, 141-144. [CrossRef] [PubMed]

36. Yamauchi, L.M.; Coppi, A.; Snounou, G.; Sinnis, P. Plasmodium sporozoites trickle out of the injection site. Cell. Microbiol. 2007, 9, 1215-1222. [CrossRef] [PubMed]

37. Kimani, D.; Jagne, Y.J.; Cox, M.; Kimani, E.; Bliss, C.M.; Gitau, E.; Ogwang, C.; Afolabi, M.O.; Bowyer, G.; Collins, K.A.; et al. Translating the immunogenicity of prime-boost immunization with ChAd63 and MVA ME-TRAP from malaria naive to malaria-endemic populations. Mol. Ther. 2014, 22, 1992-2003. [CrossRef] [PubMed]

38. Moorthy, V.S.; McConkey, S.; Roberts, M.; Gothard, P.; Arulanantham, N.; Degano, P.; Schneider, J.; Hannan, C.; Roy, M.; Gilbert, S.C.; et al. Safety of DNA and modified vaccinia virus Ankara vaccines against liver-stage P. falciparum malaria in non-immune volunteers. Vaccine 2003, 21, 1995-2002. [CrossRef]

39. Rathore, D.; Sacci, J.B.; de la Vega, P.; McCutchan, T.F. Binding and invasion of liver cells by Plasmodium falciparum sporozoites. Essential involvement of the amino terminus of circumsporozoite protein. J. Biol. Chem. 2002, 277, 7092-7098. [CrossRef] [PubMed]

40. Bongfen, S.E.; Ntsama, P.M.; Offner, S.; Smith, T.; Felger, I.; Tanner, M.; Alonso, P.; Nebie, I.; Romero, J.F.; Silvie, O.; et al. The N-terminal domain of Plasmodium falciparum circumsporozoite protein represents a target of protective immunity. Vaccine 2009, 27, 328-335. [CrossRef] [PubMed]

41. Lopez, J.A.; Weilenman, C.; Audran, R.; Roggero, M.A.; Bonelo, A.; Tiercy, J.M.; Spertini, F.; Corradin, G. A synthetic malaria vaccine elicits a potent CD8(+) and CD4(+) T lymphocyte immune response in humans. Implications for vaccination strategies. Eur. J. Immunol. 2001, 31, 1989-1998. [CrossRef] 
42. Audran, R.; Lurati-Ruiz, F.; Genton, B.; Blythman, H.E.; Ofori-Anyinam, O.; Reymond, C.; Corradin, G.; Spertini, F. The synthetic Plasmodium falciparum circumsporozoite peptide PfCS102 as a malaria vaccine candidate: A randomized controlled phase I trial. PLoS ONE 2009, 4, e7304. [CrossRef]

43. Langowski, M.D.; Khan, F.A.; Bitzer, A.A.; Genito, C.J.; Schrader, A.J.; Martin, M.L.; Soto, K.; Zou, X.; Hadiwidjojo, S.; Beck, Z.; et al. Optimization of a Plasmodium falciparum circumsporozoite protein repeat vaccine using the tobacco mosaic virus platform. Proc. Natl. Acad. Sci. USA 2020, 117, 3114-3122. [CrossRef] [PubMed]

44. Didierlaurent, A.M.; Morel, S.; Lockman, L.; Giannini, S.L.; Bisteau, M.; Carlsen, H.; Kielland, A.; Vosters, O.; Vanderheyde, N.; Schiavetti, F.; et al. AS04, an aluminum salt- and TLR4 agonist-based adjuvant system, induces a transient localized innate immune response leading to enhanced adaptive immunity. J. Immunol. 2009, 183, 6186-6197. [CrossRef] [PubMed]

45. Schijns, V.E.; Lavelle, E.C. Trends in vaccine adjuvants. Expert Rev. Vaccines 2011, 10, 539-550. [CrossRef] [PubMed]

46. Heppner, D.G., Jr.; Kester, K.E.; Ockenhouse, C.F.; Tornieporth, N.; Ofori, O.; Lyon, J.A.; Stewart, V.A.; Dubois, P.; Lanar, D.E.; Krzych, U.; et al. Towards an RTS, S-based, multi-stage, multi-antigen vaccine against falciparum malaria: Progress at the Walter Reed Army Institute of Research. Vaccine 2005, 23, 2243-2250. [CrossRef] [PubMed]

47. Caro-Aguilar, I.; Rodriguez, A.; Calvo-Calle, J.M.; Guzman, F.; De la Vega, P.; Patarroyo, M.E.; Galinski, M.R.; Moreno, A. Plasmodium vivax promiscuous T-helper epitopes defined and evaluated as linear peptide chimera immunogens. Infect. Immun. 2002, 70, 3479-3492. [CrossRef]

48. Collins, K.A.; Snaith, R.; Cottingham, M.G.; Gilbert, S.C.; Hill, A.V.S. Enhancing protective immunity to malaria with a highly immunogenic virus-like particle vaccine. Sci. Rep. 2017, 7, 46621. [CrossRef]

49. Safety, Immunogenicity and Efficacy of R21 Matrix-M in 5-17 Month Old Children in Nanoro, Burkina Faso. Available online: https://clinicaltrials.gov/ct2/show/NCT03896724 (accessed on 20 July 2020).

50. Schneider, J.; Gilbert, S.C.; Blanchard, T.J.; Hanke, T.; Robson, K.J.; Hannan, C.M.; Becker, M.; Sinden, R.; Smith, G.L.; Hill, A.V. Enhanced immunogenicity for CD8+ T cell induction and complete protective efficacy of malaria DNA vaccination by boosting with modified vaccinia virus Ankara. Nat. Med. 1998, 4, $397-402$. [CrossRef]

51. Webster, D.P.; Dunachie, S.; McConkey, S.; Poulton, I.; Moore, A.C.; Walther, M.; Laidlaw, S.M.; Peto, T.; Skinner, M.A.; Gilbert, S.C.; et al. Safety of recombinant fowlpox strain FP9 and modified vaccinia virus Ankara vaccines against liver-stage P. falciparum malaria in non-immune volunteers. Vaccine 2006, 24, 3026-3034. [CrossRef]

52. Swadling, L.; Capone, S.; Antrobus, R.D.; Brown, A.; Richardson, R.; Newell, E.W.; Halliday, J.; Kelly, C.; Bowen, D.; Fergusson, J.; et al. A human vaccine strategy based on chimpanzee adenoviral and MVA vectors that primes, boosts, and sustains functional HCV-specific T cell memory. Sci. Transl. Med. 2014, 6, 261 ra153. [CrossRef]

53. Degano, P.; Schneider, J.; Hannan, C.M.; Gilbert, S.C.; Hill, A.V. Gene gun intradermal DNA immunization followed by boosting with modified vaccinia virus Ankara: Enhanced CD8+ T cell immunogenicity and protective efficacy in the influenza and malaria models. Vaccine 1999, 18, 623-632. [CrossRef]

54. Tiono, A.B.; Nebie, I.; Anagnostou, N.; Coulibaly, A.S.; Bowyer, G.; Lam, E.; Bougouma, E.C.; Ouedraogo, A.; Yaro, J.B.B.; Barry, A.; et al. First field efficacy trial of the ChAd63 MVA ME-TRAP vectored malaria vaccine candidate in 5-17 months old infants and children. PLoS ONE 2018, 13, e0208328. [CrossRef] [PubMed]

55. Ewer, K.J.; O’Hara, G.A.; Duncan, C.J.; Collins, K.A.; Sheehy, S.H.; Reyes-Sandoval, A.; Goodman, A.L.; Edwards, N.J.; Elias, S.C.; Halstead, F.D.; et al. Protective CD8+ T-cell immunity to human malaria induced by chimpanzee adenovirus-MVA immunisation. Nat. Commun. 2013, 4, 2836. [CrossRef]

56. Hodgson, S.H.; Ewer, K.J.; Bliss, C.M.; Edwards, N.J.; Rampling, T.; Anagnostou, N.A.; de Barra, E.; Havelock, T.; Bowyer, G.; Poulton, I.D.; et al. Evaluation of the efficacy of ChAd63-MVA vectored vaccines expressing circumsporozoite protein and ME-TRAP against controlled human malaria infection in malaria-naive individuals. J. Infect. Dis. 2015, 211, 1076-1086. [CrossRef]

57. Rampling, T.; Ewer, K.J.; Bowyer, G.; Edwards, N.J.; Wright, D.; Sridhar, S.; Payne, R.; Powlson, J.; Bliss, C.; Venkatraman, N.; et al. Safety and efficacy of novel malaria vaccine regimens of RTS, S/AS01B alone, or with concomitant ChAd63-MVA-vectored vaccines expressing ME-TRAP. NPJ Vaccines 2018, 3, 49. [CrossRef] 
58. de Barra, E.; Hodgson, S.H.; Ewer, K.J.; Bliss, C.M.; Hennigan, K.; Collins, A.; Berrie, E.; Lawrie, A.M.; Gilbert, S.C.; Nicosia, A.; et al. A phase Ia study to assess the safety and immunogenicity of new malaria vaccine candidates ChAd63 CS administered alone and with MVA CS. PLoS ONE 2014, 9, e115161. [CrossRef] [PubMed]

59. Halbroth, B.R.; Sebastian, S.; Salman, A.M.; Ulaszewska, M.; Gola, A.; Longley, R.J.; Janse, C.J.; Khan, S.M.; Hill, A.V.S.; Spencer, A.J. Preclinical Development and Assessment of Viral Vectors Expressing a Fusion Antigen of Plasmodium falciparum LSA1 and LSAP2 for Efficacy against Liver-Stage Malaria. Infect. Immun. 2020, 88. [CrossRef] [PubMed]

60. Hillier, C.J.; Ware, L.A.; Barbosa, A.; Angov, E.; Lyon, J.A.; Heppner, D.G.; Lanar, D.E. Process development and analysis of liver-stage antigen 1 , a preerythrocyte-stage protein-based vaccine for Plasmodium falciparum. Infect. Immun. 2005, 73, 2109-2115. [CrossRef] [PubMed]

61. Mikolajczak, S.A.; Sacci, J.B., Jr.; De La Vega, P.; Camargo, N.; VanBuskirk, K.; Krzych, U.; Cao, J.; Jacobs-Lorena, M.; Cowman, A.F.; Kappe, S.H. Disruption of the Plasmodium falciparum liver-stage antigen-1 locus causes a differentiation defect in late liver-stage parasites. Cell Microbiol. 2011, 13, 1250-1260. [CrossRef]

62. Kariu, T.; Ishino, T.; Yano, K.; Chinzei, Y.; Yuda, M. CelTOS, a novel malarial protein that mediates transmission to mosquito and vertebrate hosts. Mol. Microbiol. 2006, 59, 1369-1379. [CrossRef]

63. Jimah, J.R.; Salinas, N.D.; Sala-Rabanal, M.; Jones, N.G.; Sibley, L.D.; Nichols, C.G.; Schlesinger, P.H.; Tolia, N.H. Malaria parasite CelTOS targets the inner leaflet of cell membranes for pore-dependent disruption. eLife 2016, 5. [CrossRef] [PubMed]

64. Shamriz, S.; Ofoghi, H. Expression of Recombinant PfCelTOS Antigen in the Chloroplast of Chlamydomonas reinhardtii and its Potential Use in Detection of Malaria. Mol. Biotechnol. 2019, 61, 102-110. [CrossRef] [PubMed]

65. Bergmann-Leitner, E.S.; Legler, P.M.; Savranskaya, T.; Ockenhouse, C.F.; Angov, E. Cellular and humoral immune effector mechanisms required for sterile protection against sporozoite challenge induced with the novel malaria vaccine candidate CelTOS. Vaccine 2011, 29, 5940-5949. [CrossRef] [PubMed]

66. Pirahmadi, S.; Zakeri, S.; Mehrizi, A.A.; Djadid, N.D.; Raz, A.A.; Sani, J.J. Combining Monophosphoryl Lipid A (MPL), CpG Oligodeoxynucleotide (ODN), and QS-21 Adjuvants Induces Strong and Persistent Functional Antibodies and T Cell Responses against Cell-Traversal Protein for Ookinetes and Sporozoites (CelTOS) of Plasmodium falciparum in BALB/c Mice. Infect. Immun. 2019, 87. [CrossRef]

67. Hutchings, C.L.; Birkett, A.J.; Moore, A.C.; Hill, A.V. Combination of protein and viral vaccines induces potent cellular and humoral immune responses and enhanced protection from murine malaria challenge. Infect. Immun. 2007, 75, 5819-5826. [CrossRef]

68. Nussenzweig, R.S.; Krettli, A.U. Breakthroughs towards a malaria vaccine. Hist Cienc Saude Manguinhos 2011, 18, 559-564. [CrossRef]

69. Orjih, A.U.; Cochrane, A.H.; Nussenzweig, R.S. Comparative studies on the immunogenicity of infective and attenuated sporozoites of Plasmodium berghei. Trans. R. Soc. Trop. Med. Hyg. 1982, 76, 57-61. [CrossRef]

70. Belnoue, E.; Costa, F.T.; Frankenberg, T.; Vigario, A.M.; Voza, T.; Leroy, N.; Rodrigues, M.M.; Landau, I.; Snounou, G.; Renia, L. Protective T cell immunity against malaria liver stage after vaccination with live sporozoites under chloroquine treatment. J. Immunol. 2004, 172, 2487-2495. [CrossRef] [PubMed]

71. Mordmuller, B.; Surat, G.; Lagler, H.; Chakravarty, S.; Ishizuka, A.S.; Lalremruata, A.; Gmeiner, M.; Campo, J.J.; Esen, M.; Ruben, A.J.; et al. Sterile protection against human malaria by chemoattenuated PfSPZ vaccine. Nature 2017, 542, 445-449. [CrossRef] [PubMed]

72. Roestenberg, M.; Teirlinck, A.C.; McCall, M.B.; Teelen, K.; Makamdop, K.N.; Wiersma, J.; Arens, T.; Beckers, P.; van Gemert, G.; van de Vegte-Bolmer, M.; et al. Long-term protection against malaria after experimental sporozoite inoculation: An open-label follow-up study. Lancet 2011, 377, 1770-1776. [CrossRef]

73. Walk, J.; Reuling, I.J.; Behet, M.C.; Meerstein-Kessel, L.; Graumans, W.; van Gemert, G.J.; Siebelink-Stoter, R.; van de Vegte-Bolmer, M.; Janssen, T.; Teelen, K.; et al. Modest heterologous protection after Plasmodium falciparum sporozoite immunization: A double-blind randomized controlled clinical trial. BMC Med. 2017, 15, 168. [CrossRef] [PubMed]

74. Richie, T.L.; Billingsley, P.F.; Sim, B.K.; James, E.R.; Chakravarty, S.; Epstein, J.E.; Lyke, K.E.; Mordmuller, B.; Alonso, P.; Duffy, P.E.; et al. Progress with Plasmodium falciparum sporozoite (PfSPZ)-based malaria vaccines. Vaccine 2015, 33, 7452-7461. [CrossRef] 
75. White, N.J. Antimalarial drug resistance. J. Clin. Invest. 2004, 113, 1084-1092. [CrossRef]

76. Nussenzweig, R.S.; Vanderberg, J.; Most, H.; Orton, C. Protective immunity produced by the injection of x-irradiated sporozoites of plasmodium berghei. Nature 1967, 216, 160-162. [CrossRef]

77. Kurup, S.P.; Anthony, S.M.; Hancox, L.S.; Vijay, R.; Pewe, L.L.; Moioffer, S.J.; Sompallae, R.; Janse, C.J.; Khan, S.M.; Harty, J.T. Monocyte-Derived CD11c(+) Cells Acquire Plasmodium from Hepatocytes to Prime CD8 T Cell Immunity to Liver-Stage Malaria. Cell Host Microbe 2019, 25, 565-577. [CrossRef]

78. Hoffman, S.L.; Goh, L.M.; Luke, T.C.; Schneider, I.; Le, T.P.; Doolan, D.L.; Sacci, J.; de la Vega, P.; Dowler, M.; Paul, C.; et al. Protection of humans against malaria by immunization with radiation-attenuated Plasmodium falciparum sporozoites. J. Infect. Dis. 2002, 185, 1155-1164. [CrossRef]

79. Doolan, D.L.; Hoffman, S.L. IL-12 and NK cells are required for antigen-specific adaptive immunity against malaria initiated by CD8+ T cells in the Plasmodium yoelii model. J. Immunol. 1999, 163, 884-892. [PubMed]

80. Sissoko, M.S.; Healy, S.A.; Katile, A.; Omaswa, F.; Zaidi, I.; Gabriel, E.E.; Kamate, B.; Samake, Y.; Guindo, M.A.; Dolo, A.; et al. Safety and efficacy of PfSPZ Vaccine against Plasmodium falciparum via direct venous inoculation in healthy malaria-exposed adults in Mali: A randomised, double-blind phase 1 trial. Lancet Infect. Dis. 2017, 17, 498-509. [CrossRef]

81. Epstein, J.E.; Richie, T.L. The whole parasite, pre-erythrocytic stage approach to malaria vaccine development: A review. Curr. Opin. Infect. Dis. 2013, 26, 420-428. [CrossRef]

82. Seder, R.A.; Chang, L.J.; Enama, M.E.; Zephir, K.L.; Sarwar, U.N.; Gordon, I.J.; Holman, L.A.; James, E.R.; Billingsley, P.F.; Gunasekera, A.; et al. Protection against malaria by intravenous immunization with a nonreplicating sporozoite vaccine. Science 2013, 341, 1359-1365. [CrossRef]

83. Epstein, J.E.; Tewari, K.; Lyke, K.E.; Sim, B.K.; Billingsley, P.F.; Laurens, M.B.; Gunasekera, A.; Chakravarty, S.; James, E.R.; Sedegah, M.; et al. Live attenuated malaria vaccine designed to protect through hepatic CD8(+) T cell immunity. Science 2011, 334, 475-480. [CrossRef]

84. McColm, A.A.; Dalton, L. Heterologous immunity in rodent malaria: Comparison of the degree of cross-immunity generated by vaccination with that produced by exposure to live infection. Ann. Trop. Med. Parasitol. 1983, 77, 355-377. [CrossRef] [PubMed]

85. Vanderberg, J.P.; Frevert, U. Intravital microscopy demonstrating antibody-mediated immobilisation of Plasmodium berghei sporozoites injected into skin by mosquitoes. Int. J. Parasitol. 2004, 34, 991-996. [CrossRef] [PubMed]

86. Roestenberg, M.; McCall, M.; Hopman, J.; Wiersma, J.; Luty, A.J.; van Gemert, G.J.; van de Vegte-Bolmer, M.; van Schaijk, B.; Teelen, K.; Arens, T.; et al. Protection against a malaria challenge by sporozoite inoculation. N. Engl. J. Med. 2009, 361, 468-477. [CrossRef] [PubMed]

87. Hoffman, S.L.; Billingsley, P.F.; James, E.; Richman, A.; Loyevsky, M.; Li, T.; Chakravarty, S.; Gunasekera, A.; Chattopadhyay, R.; Li, M.; et al. Development of a metabolically active, non-replicating sporozoite vaccine to prevent Plasmodium falciparum malaria. Hum. Vaccines 2010, 6, 97-106. [CrossRef] [PubMed]

88. Mueller, A.K.; Labaied, M.; Kappe, S.H.; Matuschewski, K. Genetically modified Plasmodium parasites as a protective experimental malaria vaccine. Nature 2005, 433, 164-167. [CrossRef] [PubMed]

89. Vaughan, A.M.; Wang, R.; Kappe, S.H. Genetically engineered, attenuated whole-cell vaccine approaches for malaria. Hum. Vaccines 2010, 6, 107-113. [CrossRef]

90. Kublin, J.G.; Mikolajczak, S.A.; Sack, B.K.; Fishbaugher, M.E.; Seilie, A.; Shelton, L.; VonGoedert, T.; Firat, M.; Magee, S.; Fritzen, E.; et al. Complete attenuation of genetically engineered Plasmodium falciparum sporozoites in human subjects. Sci. Transl. Med. 2017, 9. [CrossRef]

91. Butler, N.S.; Schmidt, N.W.; Vaughan, A.M.; Aly, A.S.; Kappe, S.H.; Harty, J.T. Superior antimalarial immunity after vaccination with late liver stage-arresting genetically attenuated parasites. Cell Host Microbe 2011, 9 , 451-462. [CrossRef]

92. Mikolajczak, S.A.; Silva-Rivera, H.; Peng, X.; Tarun, A.S.; Camargo, N.; Jacobs-Lorena, V.; Daly, T.M.; Bergman, L.W.; de la Vega, P.; Williams, J.; et al. Distinct malaria parasite sporozoites reveal transcriptional changes that cause differential tissue infection competence in the mosquito vector and mammalian host. Mol. Cell Biol. 2008, 28, 6196-6207. [CrossRef]

93. Kaiser, K.; Matuschewski, K.; Camargo, N.; Ross, J.; Kappe, S.H. Differential transcriptome profiling identifies Plasmodium genes encoding pre-erythrocytic stage-specific proteins. Mol. Microbiol. 2004, 51, 1221-1232. [CrossRef] [PubMed] 
94. Tarun, A.S.; Dumpit, R.F.; Camargo, N.; Labaied, M.; Liu, P.; Takagi, A.; Wang, R.; Kappe, S.H.I. Protracted sterile protection with Plasmodium yoelii pre-erythrocytic genetically attenuated parasite malaria vaccines is independent of significant liver-stage persistence and is mediated by CD8+ T cells. J. Infect. Dis. 2007, 196, 608-616. [CrossRef] [PubMed]

95. Jobe, O.; Donofrio, G.; Sun, G.; Liepinsh, D.; Schwenk, R.; Krzych, U. Immunization with radiation-attenuated Plasmodium berghei sporozoites induces liver cCD8alpha+DC that activate CD8+T cells against liver-stage malaria. PLoS ONE 2009, 4, e5075. [CrossRef] [PubMed]

96. Annoura, T.; van Schaijk, B.C.; Ploemen, I.H.; Sajid, M.; Lin, J.W.; Vos, M.W.; Dinmohamed, A.G.; Inaoka, D.K.; Rijpma, S.R.; van Gemert, G.J.; et al. Two Plasmodium 6-Cys family-related proteins have distinct and critical roles in liver-stage development. FASEB J. 2014, 28, 2158-2170. [CrossRef] [PubMed]

97. Arredondo, S.A.; Swearingen, K.E.; Martinson, T.; Steel, R.; Dankwa, D.A.; Harupa, A.; Camargo, N.; Betz, W.; Vigdorovich, V.; Oliver, B.G.; et al. The Micronemal Plasmodium Proteins P36 and P52 Act in Concert to Establish the Replication-Permissive Compartment Within Infected Hepatocytes. Front. Cell. Infect. Microbiol. 2018, 8, 413. [CrossRef]

98. van Schaijk, B.C.; Ploemen, I.H.; Annoura, T.; Vos, M.W.; Foquet, L.; van Gemert, G.J.; Chevalley-Maurel, S.; van de Vegte-Bolmer, M.; Sajid, M.; Franetich, J.F.; et al. A genetically attenuated malaria vaccine candidate based on P. falciparum b9/slarp gene-deficient sporozoites. eLife 2014, 3. [CrossRef]

99. Labaied, M.; Harupa, A.; Dumpit, R.F.; Coppens, I.; Mikolajczak, S.A.; Kappe, S.H. Plasmodium yoelii sporozoites with simultaneous deletion of P52 and P36 are completely attenuated and confer sterile immunity against infection. Infect. Immun. 2007, 75, 3758-3768. [CrossRef] [PubMed]

100. Annoura, T.; Ploemen, I.H.; van Schaijk, B.C.; Sajid, M.; Vos, M.W.; van Gemert, G.J.; Chevalley-Maurel, S.; Franke-Fayard, B.M.; Hermsen, C.C.; Gego, A.; et al. Assessing the adequacy of attenuation of genetically modified malaria parasite vaccine candidates. Vaccine 2012, 30, 2662-2670. [CrossRef]

101. Aly, A.S.; Mikolajczak, S.A.; Rivera, H.S.; Camargo, N.; Jacobs-Lorena, V.; Labaied, M.; Coppens, I.; Kappe, S.H. Targeted deletion of SAP1 abolishes the expression of infectivity factors necessary for successful malaria parasite liver infection. Mol. Microbiol. 2008, 69, 152-163. [CrossRef]

102. Spring, M.; Murphy, J.; Nielsen, R.; Dowler, M.; Bennett, J.W.; Zarling, S.; Williams, J.; de la Vega, P.; Ware, L.; Komisar, J.; et al. First-in-human evaluation of genetically attenuated Plasmodium falciparum sporozoites administered by bite of Anopheles mosquitoes to adult volunteers. Vaccine 2013, 31, 4975-4983. [CrossRef]

103. Roestenberg, M.; Walk, J.; van der Boor, S.C.; Langenberg, M.C.C.; Hoogerwerf, M.A.; Janse, J.J.; Manurung, M.; Yap, X.Z.; Garcia, A.F.; Koopman, J.P.R.; et al. A double-blind, placebo-controlled phase 1/2a trial of the genetically attenuated malaria vaccine PfSPZ-GA1. Sci. Transl. Med. 2020, 12. [CrossRef]

104. Kappe, S.H.; Vaughan, A.M.; Boddey, J.A.; Cowman, A.F. That was then but this is now: Malaria research in the time of an eradication agenda. Science 2010, 328, 862-866. [CrossRef]

105. Gantz, V.M.; Jasinskiene, N.; Tatarenkova, O.; Fazekas, A.; Macias, V.M.; Bier, E.; James, A.A. Highly efficient Cas9-mediated gene drive for population modification of the malaria vector mosquito Anopheles stephensi. Proc. Natl. Acad. Sci. USA 2015, 112, E6736-E6743. [CrossRef]

106. Kudyba, H.M.; Cobb, D.W.; Florentin, A.; Krakowiak, M.; Muralidharan, V. CRISPR/Cas9 Gene Editing to Make Conditional Mutants of Human Malaria Parasite, P. falciparum. J. Vis. Exp. 2018, 139, 57747. [CrossRef]

107. Lee, M.C.S.; Lindner, S.E.; Lopez-Rubio, J.J.; Llinas, M. Cutting back malaria: CRISPR/Cas9 genome editing of Plasmodium. Brief. Funct. Genom. 2019, 18, 281-289. [CrossRef]

108. Hammond, A.; Galizi, R.; Kyrou, K.; Simoni, A.; Siniscalchi, C.; Katsanos, D.; Gribble, M.; Baker, D.; Marois, E.; Russell, S.; et al. A CRISPR-Cas9 gene drive system targeting female reproduction in the malaria mosquito vector Anopheles gambiae. Nat. Biotechnol. 2016, 34, 78-83. [CrossRef]

109. Kurup, S.P.; Tarleton, R.L. Perpetual expression of PAMPs necessary for optimal immune control and clearance of a persistent pathogen. Nat. Commun. 2013, 4, 2616. [CrossRef]

110. Doolan, D.L.; Dobano, C.; Baird, J.K. Acquired immunity to malaria. Clin. Microbiol. Rev. 2009, 22 , 13-36. [CrossRef] [PubMed]

(C) 2020 by the authors. Licensee MDPI, Basel, Switzerland. This article is an open access article distributed under the terms and conditions of the Creative Commons Attribution (CC BY) license (http://creativecommons.org/licenses/by/4.0/). 